\section{A SHIFT IN SUGAR ATTITUDES}

Sir, I was interested to read about the launch of the new group 'Action on Sugar' in the press.

This group has been implemented to try to persuade food producers to reduce the amount of hidden sugars in processed foods such as tomato ketchup and coleslaw, and therefore reduce the general population's sugar intake. Their aim is to tackle the so called 'obesity crisis' and the development of diseases such as type 2 diabetes; a welcome side effect of this could be a reduction in caries rate.

Although the group feels that a 20$30 \%$ reduction in added sugars will be possible over five years, a more immediate benefit could be a shift in attitudes towards sugar amongst the general public due to media interest. It is clear that most adults know that sugar is damaging to oral health, but in communities where many people are partially dentate, decay is accepted as a fact of life and there is little stigma associated with tooth loss.

Perhaps if there becomes a greater awareness of the role of dietary sugar in serious medical conditions such as diabetes, dental health will stand to benefit alongside prevention of these conditions.

J. Humphreys

DOI: 10.1038/sj.bdj.2014.57 letters about the BDA's commitment and contribution to preserving the profession's heritage are taken very seriously. In many ways they reflect the wider challenges that we have faced in making the necessary adjustments to the way the BDA is organised to meet member needs.

The BDA as an organisation fulfils a very diverse range of functions and different members value each of those activities to different extents. As a consequence, the decisions about where savings could be made were really difficult: what is important to one cohort of the profession is less so to another.

We have thought hard about what we must do to preserve the sustainability of the whole of the Association for the whole of the profession in the long term. Sadly, this has meant that we must temporarily scale back our activities in the Museum as a whole, including the Education service. That said we will be continuing activity within the museum albeit at somewhat reduced level. Revised ways of working should mean that our heritage and social contribution can be maintained. We will do what we can to augment the service once again when funds permit.

DOI: 10.1038/sj.bdj.2014.55

\section{ORTHODONTICS}

\section{Sixty minutes changed my life}

Sir, have you ever heard or seen something that had such a profound effect on you, that you could no longer ignore it? Such an event happened to me over 20 years ago during a one-day seminar on functional jaw orthopaedics. As the last lecturer took to the podium for his 60 minute presentation, I could only think of slipping out quietly and heading for the nearest pub! I am so glad I didn't. His first slide was of an Etruscan mummy depicting severe facial pain; the next was of a patient who was in such pain she could hardly open her mouth. The audience was asked, "would you want to treat this patient orthodontically? Why would you? Surely it would make better sense to relieve the patient's pain and restore normal mouth opening prior to any orthodontic treatment?'

That lecture changed my entire attitude to orthodontics and from that moment on I was determined to learn as much as I could about temporomandibular joint dysfunction (TMJD). All the years of undergraduate and postgraduate training in orthodontics now gave me a new purpose. It made me realise that orthodontics was a means to an end and not the end in itself. In other words, why undertake treatment on dysfunctional joints with internal derangement? Why then is TMJ function so important, or is it? Part of the answer depends on what extent a practitioner looks for the signs and symptoms attributable to TMJD, which include facial pain, limited mouth opening, ear pain, ear fullness, head pain, pain on chewing; amongst others. Just as a periodontal probe is an absolute necessity for a complete examination for periodontal disease, so the mm ruler is an absolute necessity in the complete examination of a patient for possible TMJD.

The range of motion of a joint is basic information for any patient with a joint disorder. The only way a clinical dentist can exclude him/herself from examining for TMJD is NOT to examine patients.

\section{P. Grossmann}

By email

DOI: 10.1038/sj.bdj.2014.56 